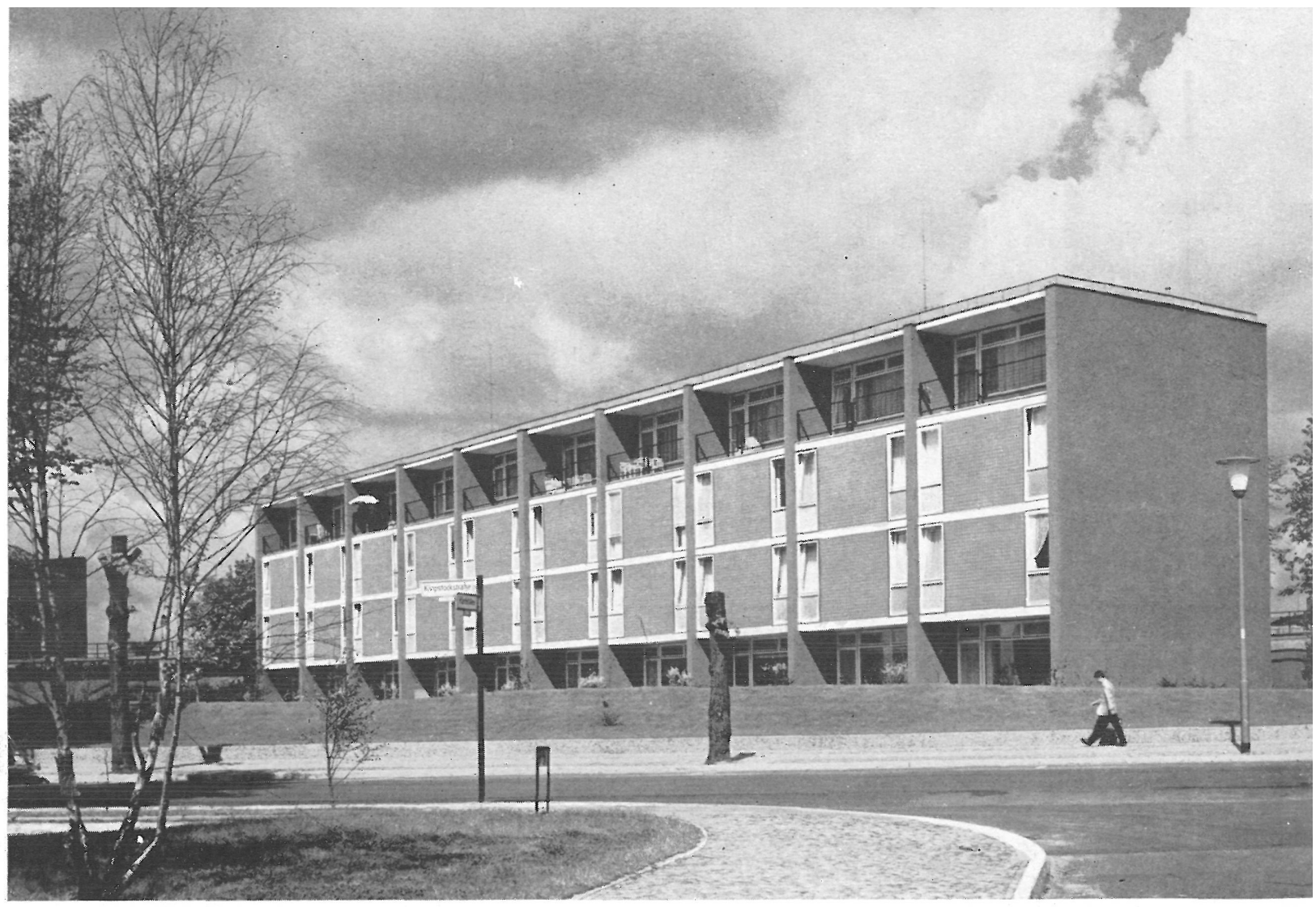

123.63

\title{
viviendas, en Berlín
}

\section{P. SCHNEIDER-ESLEBEN, arquitecto}

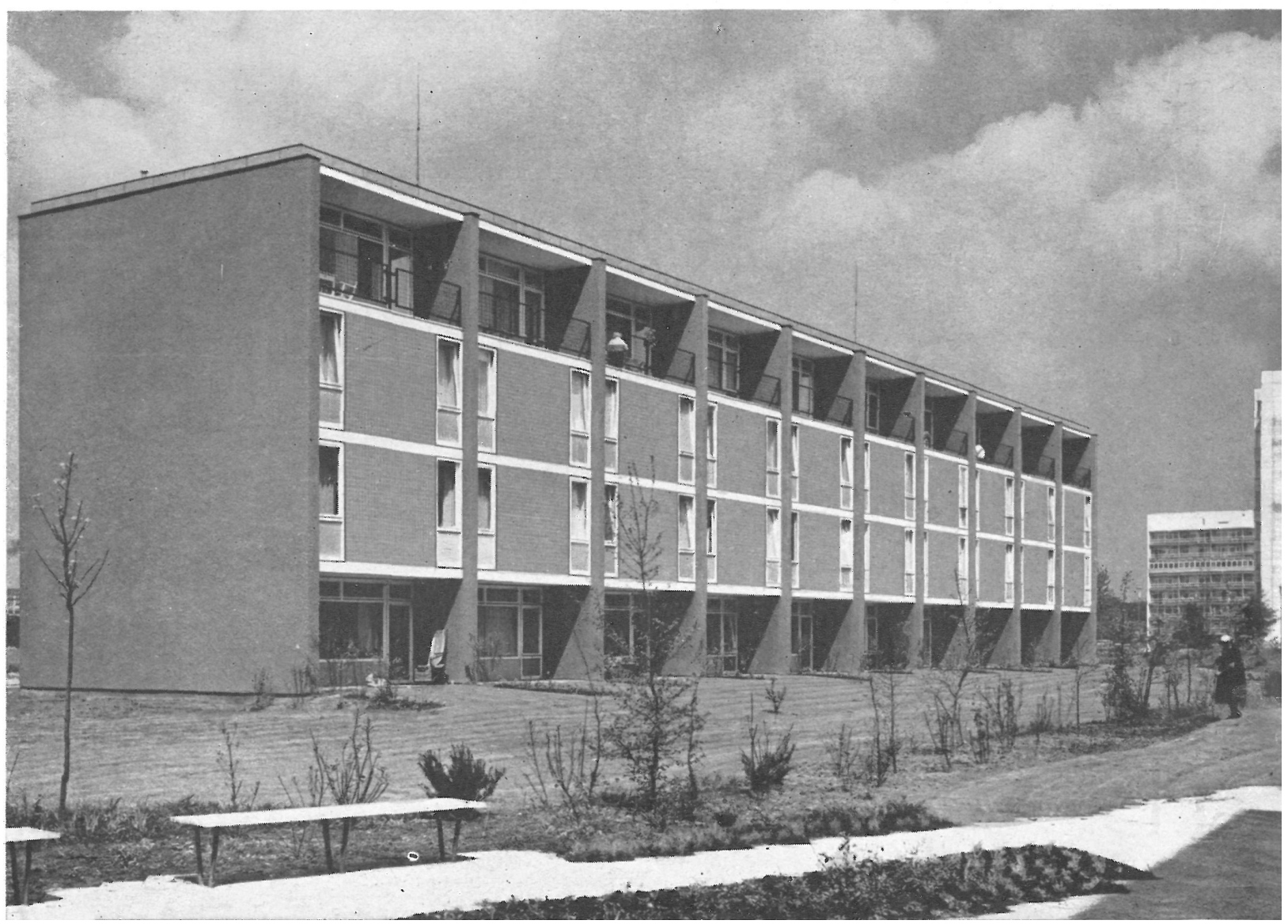




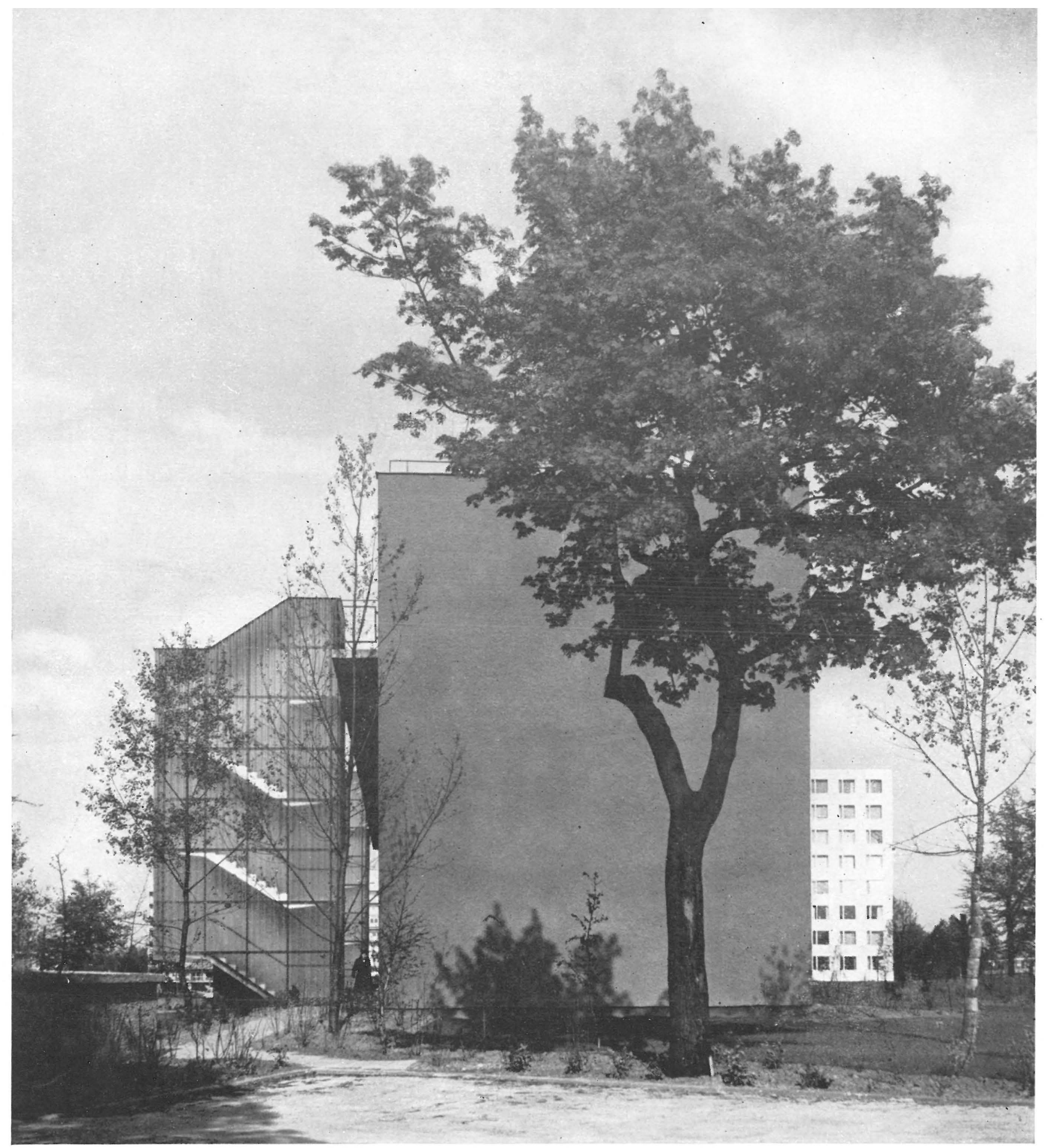

Este edificio de cuatro plantas corresponde a un grupo de cinco construcciones iguales situadas al norte de la parcela que constituye el barrio Hansa, entre la calle Klopstock y el Stadt-Bahn, famoso ferrocarril urbano berlinés.

El bloque de $56 \mathrm{~m}$ de longitud por 9 de anchura y 12 de altura, consta de veinte viviendas. Cada vivienda, de $77 \mathrm{~m}^{2}$, está distribuída en dos plantas: la baja aloja el cuarto de estar y la cocina y la alta el baño y los dormitorios. 

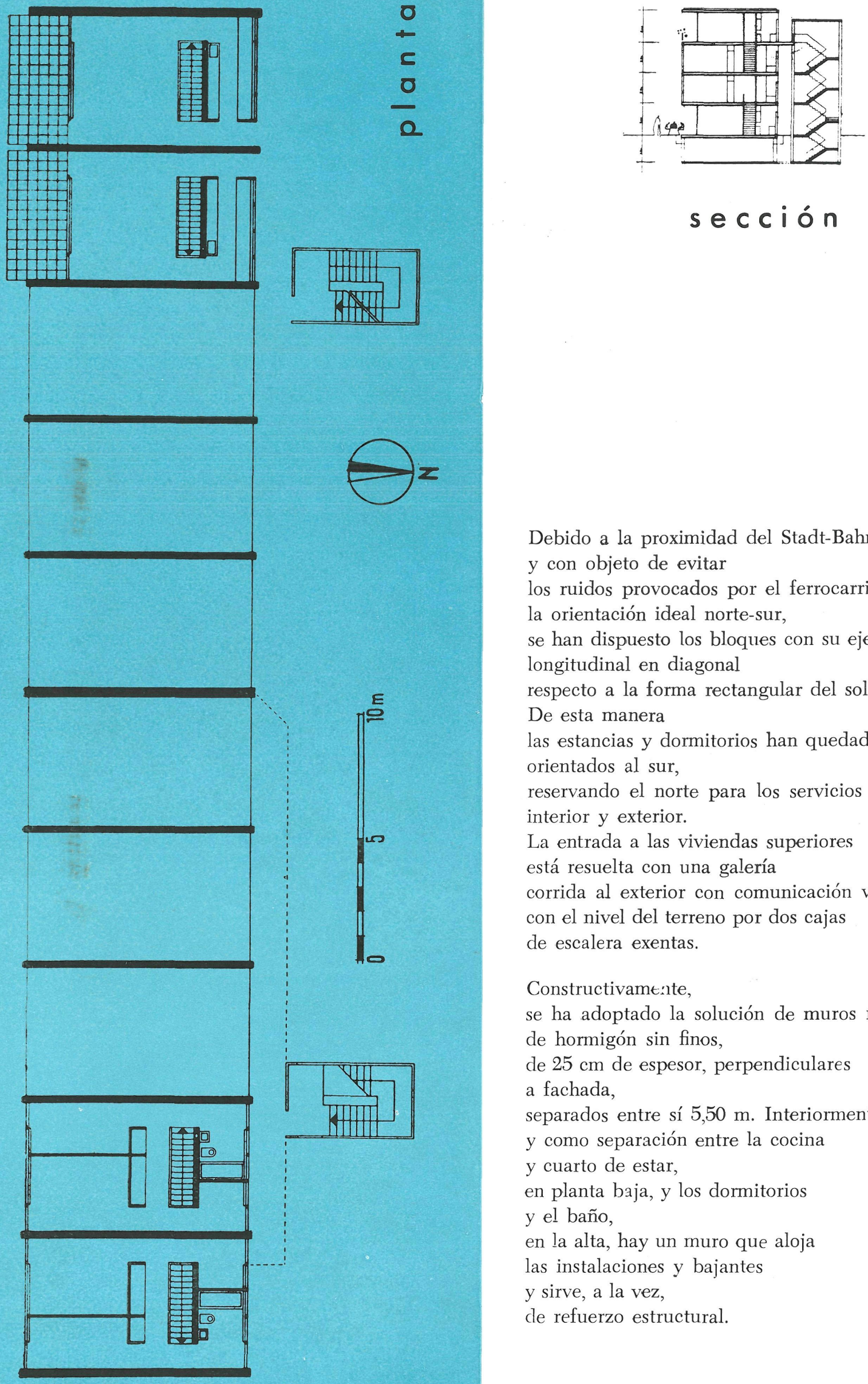

sección

Debido a la proximidad del Stadt-Bahn, y con objeto de evitar

los ruidos provocados por el ferrocarril y lograr la orientación ideal norte-sur,

se han dispuesto los bloques con su eje

longitudinal en diagonal

respecto a la forma rectangular del solar.

De esta manera

las estancias y dormitorios han quedado orientados al sur,

reservando el norte para los servicios y accesos interior y exterior.

La entrada a las viviendas superiores está resuelta con una galería corrida al exterior con comunicación vertical con el nivel del terreno por dos cajas de escalera exentas.

\section{Constructivamt:ite,}

se ha adoptado la solución de muros resistentes de hormigón sin finos,

de $25 \mathrm{~cm}$ de espesor, perpendiculares

a fachada,

separados entre sí $5,50 \mathrm{~m}$. Interiormente,

y como separación entre la cocina

y cuarto de estar,

en planta baja, y los dormitorios

y el baño,

en la alta, hay un muro que aloja

las instalaciones y bajantes

y sirve, a la vez,

de refuerzo estructural. 
Dada la disposición estructural adoptada, los huecos llegan de suelo a techo. El retranqueo dispuesto en los cuartos de estar crea unas terrazas cubiertas al sur muy abrigadas. El cerramiento exterior se ha realizado alternando las superficies acristaladas con los muros de siporex revestidos de azulejos, como protección de la intemperie. El forjado de cubierta es una placa de hormigón aireado, de $16 \mathrm{~cm}$, que sirve de aislante térmico. Las escaleras de acceso a las viviendas se han cerrado exteriormente con placas onduladas de cristal translúcido. En el sótano se han previsto unos cuartos para trasteros y garaje infantil.

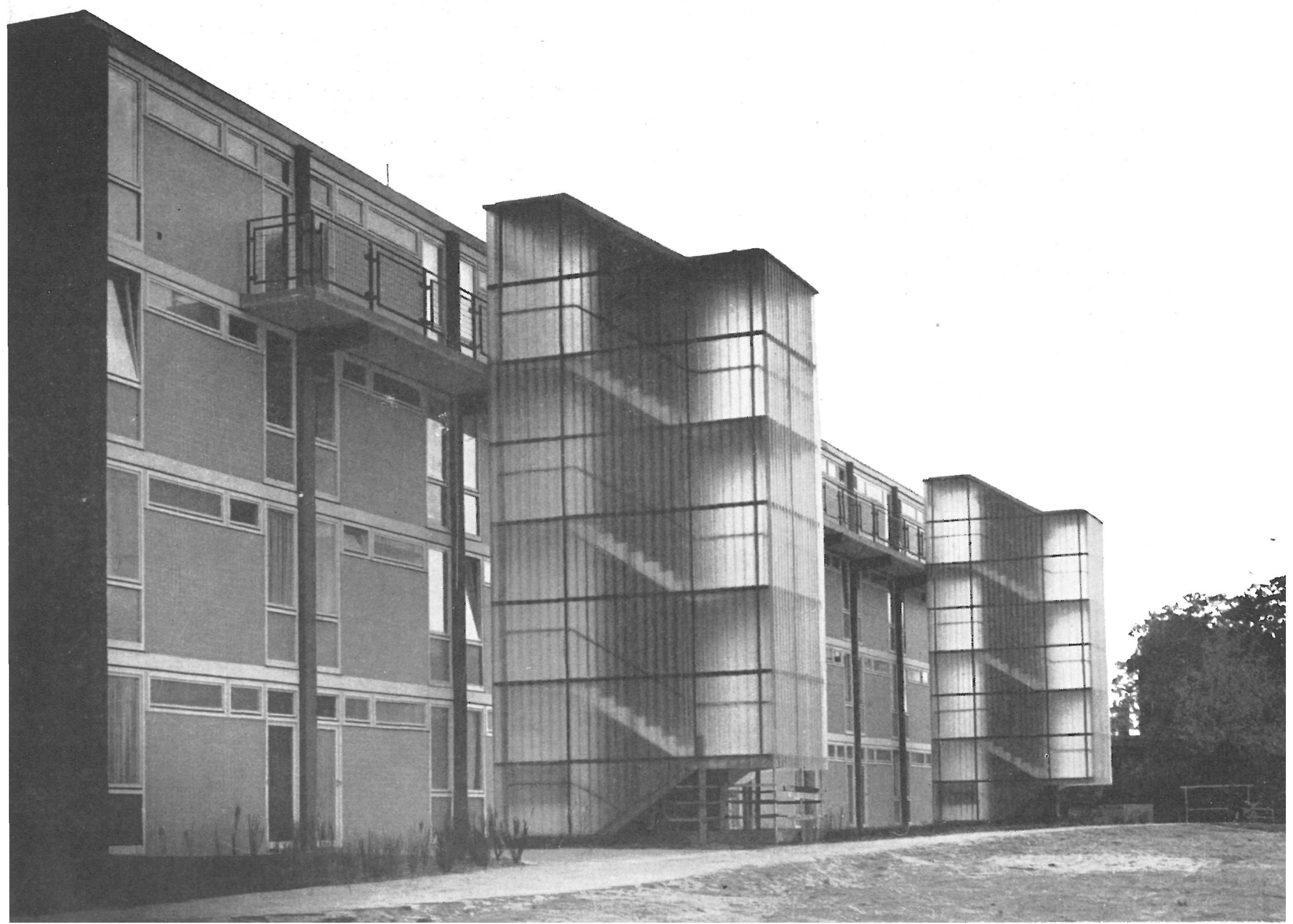

